\title{
EFFECTS OF X-RAYS UPON HAPLOID AND DIPLOID EMBRYOS OF HABROBRACON ${ }^{1}$
}

\author{
A. M. CLARK AND C. J. MITCHELL 2 \\ Dept. of Biological Sciences, University of Delaware, Newark, Delaware, and \\ Marine Biological Laboratory, Woods Hole, Mass.
}

Correlations between radiosensitivity and ploidy, the number of chromosome sets, have been made by Stadler (1929), Müntzing (1941), Fröier, Gelin and Gustafsson (1941) and Smith $(1943,1946)$ for cereals; by Latarjet and Ephrussi (1949) for the yeast, Saccaromyces; by Whiting and Bostian (1931), Clark and Kelly (1950), and Clark and Mitchell (1951) for Habrobracon ; and by Lamy and Muller (1939) for Drosophila. These studies, with the exception of the last, have been consistent in demonstrating, for the material tested, that there is a greater resistance with higher ploidy and the results have been taken as evidence that $\mathrm{x}$-radiation damage is primarily chromosomal. That there is less chance for homozygous deficiencies to occur in polyploids than in diploids and that all deficiencies in haploids would be lethal, have been given as explanations. Lamy and Muller found that diploid and triploid Drosophila x-rayed as embryos are equally radiosensitive and they assume that the deleterious effects in this case are largely non-chromosomal ("physiological").

The senior author and associates have been studying the effects of x-rays on haploids and diploids of the parasitic wasp, Habrobracon, during different stages of its life cycle in order to determine to what extent genome number can be correlated with radiosensitivity. Comparison of radiosensitivity during the pupal, prepupal and larval stages has shown that diploids are more resistant than haploids. The present paper reports on radiosensitivity during the early embryonic stages.

\section{Material and Methods}

In Habrobracon, haploid males arise from unfertilized eggs and diploids (male and female) from fertilized eggs. Whiting (1943) has established the sex-determining mechanism and has shown that cultures can be obtained that contain (1) only haploid males, (2) haploid males and diploid females, (3) haploid males, diploid females and diploid males. In the present study comparison is made between (1) and (2). Stocks No. 33 and No. 17-o (ivory) were used. Cultures of haploid embryos were obtained from No. 33 unmated mothers while cultures of haploid and diploid embryos ("mixed" cultures) were obtained from No. 33 females mated to No. $17-\mathrm{o}^{\mathrm{i}}$ males. Progeny of mated females normally consist of about 60 per cent diploids and 40 per cent haploids.

Embryos of known ages were $\mathrm{x}$-rayed. They were then (a) placed in syracuse dishes containing a mineral oil ("Nujol") and observed for hatchability or (b) sion.

1 This work was done under contract no. AT(30-1)-953 for the Atomic Energy Commis-

${ }^{2}$ Support received from University of Delaware Committee on Research. 
placed upon food (paralyzed Ephestia larvae) in order that survivors could develop into adults. All cultures were kept at $30^{\circ} \mathrm{C}$. At this temperature eggs hatch about 30 hours after being laid. The larvae in mineral oil were counted 40 hours after oviposition and the incidence of hatchability noted. Eggs placed upon Ephestia larvae were observed at various stages of development and comparison of sex ratios was made between control and treated cultures from mated females.

All microscopical studies were made upon whole mounts of embryos fixed in Kahle's fluid and stained with the Rafalko modification of the Feulgen technique.

For x-ray experiments a dual-tube self-rectifying outfit with a simultaneous cross firing technique was used. The secondary voltage was $182 \mathrm{kv}$; the tube was $25 \mathrm{ma}$; the output intensity was $110 \mathrm{r}$ per minute. There was an inherent filter equivalent to $0.2 \mathrm{~mm}$. copper. X-radiation was obtained at the Marine Biological Laboratory, Woods Hole, Massachusetts.

\section{Results}

Embryos treated between one and three hours of age

As determined by microscopical study of whole mounts, untreated embryos between one and three hours of age were found not to have progressed beyond cleavage. There is a syncytium at this stage with the nuclei rapidly undergoing synchronous mitosis. For the majority of the eggs the number of nuclei found was over fifty. A range from the pronuclear stage to embryonic stages having over

TABLE I

Hatchability ratios for eggs from mated and unmated females

(Age of embryos when $x$-rayed, 1-3 hours)

\begin{tabular}{|c|c|c|c|c|c|}
\hline \multirow{3}{*}{ Dose $(r)$} & \multirow{2}{*}{\multicolumn{2}{|c|}{$\begin{array}{l}\text { Haploids } \\
\text { (from unmated } \odot \text { ค) }\end{array}$}} & Haploids & Diploids* & \multirow{3}{*}{$\begin{array}{c}\text { Dip!oids } \\
\text { (estimated) } \\
\text { hatchability }\end{array}$} \\
\hline & & & \multicolumn{2}{|c|}{ (from mated $\odot$ ๆ) } & \\
\hline & No. eggs & Hatchability & No. eggs & Hatchability & \\
\hline 0 & 573 & $.93 \pm .01$ & 1071 & $.92 \pm .01$ & $.91 \pm .01$ \\
\hline 27.5 & 91 & $.97 \pm .02$ & 131 & $.93 \pm .02$ & $.90 \pm .04$ \\
\hline 55 & 148 & $.91 \pm .02$ & 263 & $.87 \pm .02$ & $.75 \pm .03$ \\
\hline 110 & 263 & $.85 \pm .02$ & 433 & $.47 \pm .02$ & $.22 \pm .03$ \\
\hline 165 & 220 & $.69 \pm .03$ & 168 & $.31 \pm .03$ & $.07 \pm .02$ \\
\hline 220 & 331 & $.51 \pm .03$ & 319 & $.18 \pm .02$ & .00 \\
\hline 275 & 137 & $.27 \pm .04$ & 146 & $.05 \pm .02$ & \\
\hline 330 & 195 & $.10 \pm .02$ & 225 & $.04 \pm .02$ & \\
\hline 440 & 142 & $.03 \pm .01$ & 161 & $.02 \pm .01$ & \\
\hline
\end{tabular}

* Adult female ratio in controls .60 (729/1226 adults).

250 nuclei was observed but these extremes were exceptional. Eggs from mated and unmated females were in the same stages of development.

Hatchability ratios for eggs of this age at time of treatment demonstrate that those from mated females are more sensitive than those from unmated (Table I). This difference is clearly shown after doses from $110 \mathrm{r}$ to $275 \mathrm{r}$. For example, 
after treatment with $110 \mathrm{r}$, the hatchability for eggs from mated females is $0.47 \pm .02$ as compared with $0.85 \pm .02$ for eggs from unmated mothers. Untreated eggs from mated and unmated females do not differ in hatchability (Table I). Since the incidence of female offspring from mated control mothers was found to be 0.60 on the basis of 1226 adults counted, these data can be used for deriving the hatchability of diploid eggs (Table I).

Since the hatchability data (Table I) indicate that haploids are more radioresistant, the ratio of adult females $\left(\frac{++}{\text { Total }}\right)$ from x-rayed eggs of mated mothers should be lower than from control eggs. This is substantiated when comparison is made of the ratios of haploid males and diploid females from x-rayed and control cultures (Table II). At all doses there is a marked decrease in the ratio of females. For example, after treatment with 220 r, 33 males and 6 females were obtained $(0.15 \pm .06)$ as compared with 46 males and 60 females in the untreated group $(0.57 \pm .05)$.

Reference to Table II will show that there is a decrease in hatchability with increase in dose and that this occurs for eggs from both mated and unmated females.

TABLE II

Hatchability and eclosion ratios for offspring from mated females (Age of embryos when $x$-rayed, 1 -3 hours)

\begin{tabular}{|c|c|c|c|c|c|c|}
\hline \multirow{2}{*}{ Dose (r) } & \multirow{2}{*}{ No. Eggs } & \multicolumn{2}{|c|}{ No. adults } & \multirow{2}{*}{$\frac{\text { Larvae }}{\text { Eggs }}$} & \multirow{2}{*}{$\frac{\text { Adults }}{\text { Larvae }}$} & \multirow{2}{*}{$\frac{\circ q}{\text { Total }}$} \\
\hline & & $\sigma^{7} \sigma^{7}$ & 우우 & & & \\
\hline 0 & 146 & 46 & 60 & $.84 \pm .03$ & $.86 \pm .03$ & $.57 \pm .05$ \\
\hline 55 & 116 & 43 & 43 & $.81 \pm .04$ & $.91 \pm .03$ & $.50 \pm .05$ \\
\hline 110 & 101 & 26 & 7 & $.55 \pm .05$ & $.59 \pm .07$ & $.21 \pm .07$ \\
\hline 165 & 284 & 42 & 8 & $.18 \pm .02$ & $.98 \pm .02$ & $.16 \pm .05$ \\
\hline 220 & 404 & 33 & 6 & $.11 \pm .02$ & $.86 \pm .05$ & $.15 \pm .06$ \\
\hline
\end{tabular}

Once the eggs have hatched, however, there appear to be no further deleterious effects as shown by comparison of ratios of adults/larvae at different doses. There is no developmental lag in survivors and the adults show no structural abnormalities. Death due to irradiation occurs before hatching.

Embryos that were $\mathrm{x}$-rayed (220 r) during cleavage (one-three hours of age) were fixed at an age when somites were normally present (12-15 hours of age) in the control embryos. Examination of whole mounts showed that some of these treated embryos had formed somites and appeared normal. The majority, however, were either in cleavage or early blastema. Nuclei in the cleavage stages were in interphase and were very much enlarged, being up to four times the diameter of untreated nuclei. Many were clumped together forming dark patches within the egg. The large number of nuclei in treated embryos which had died may suggest that cleavage continued after $\mathrm{x}$-radiation. In some eggs, nuclei could not be found, due, perhaps, to disintegration of chromatin material. A sufficient number of eggs from haploid and mixed cultures was not prepared to make a quantitative microscopical comparison between these groups. 
TABLE III

Hatchability and eclosion ratios for offspring from mated females (Age of embryos when $x$-rayed, 3-4 hours)

\begin{tabular}{|c|c|c|c|c|c|c|}
\hline \multirow{2}{*}{ Dose $(r)$} & \multirow{2}{*}{ No. eggs } & \multicolumn{2}{|c|}{ No. adults } & \multirow{2}{*}{$\frac{\text { Larvae }}{\text { Eggs }}$} & \multirow{2}{*}{$\frac{\text { Adults }}{\text { Larvae }}$} & \multirow{2}{*}{$\frac{9 \text { ? }}{\text { Total }}$} \\
\hline & & $\sigma^{7} \sigma^{7}$ & 우우 & & & \\
\hline $\begin{array}{r}0 \\
220\end{array}$ & $\begin{array}{l}197 \\
442\end{array}$ & $\begin{array}{l}53 \\
48\end{array}$ & $\begin{array}{r}102 \\
81\end{array}$ & $\begin{array}{l}.89 \pm .02 \\
.34 \pm .02\end{array}$ & $\begin{array}{l}.89 \pm .02 \\
.86 \pm .03\end{array}$ & $\begin{array}{l}.66 \pm .04 \\
.63 \pm .04\end{array}$ \\
\hline
\end{tabular}

Embryos treated between three and four hours of age

Embryos of three-four hours of age from mated mothers were treated with $220 \mathrm{r}$ and were allowed to develop into adults. The sex ratios of adults emerging were compared with those from control eggs (Table III). The incidence of females from control and treated eggs is not significantly different. This indicates that haploids and diploids are equally radiosensitive when treated at this stage of development. There are no developmental effects of an injurious nature after hatching as shown by the ratios of adults/larvae. Most of the three-hour old control embryos have completed cleavage and have hundreds of nuclei within the egg. These nuclei are migrating or have migrated to the periphery of the egg (blastema stage).

\section{Embryos treated between 13 and 15 hours of age}

Older embryos in the stage when somites are present that are treated with $\mathrm{x}$-rays may not show injury during the egg stages. However, deleterious effects may be seen during later stages of development. Embryos, 13-15 hours of age, were $\mathrm{x}$-rayed with either $722 \mathrm{r}$ or $1444 \mathrm{r}$. Comparison of the number of larvae obtained showed that there is no decrease in hatchability over the controls (Table IV). The number of adults, however, is markedly decreased for those treated with $1444 \mathrm{r}$. These groups tended to show a lag in development as larvae and to remain as larvae after the controls had become adults. Some of the larvae did not grow to full size, but continued development to the pupal stage without spinning a cocoon.

TABLE IV

Hatchability and eclosion ratios for offspring from mated and unmated females (Age of embryos when $x$-rayed, 13-15 hours)

\begin{tabular}{|c|c|c|c|c|c|c|c|c|}
\hline \multirow{2}{*}{ Dose (r) } & \multirow{2}{*}{ Mothers } & \multirow{2}{*}{ No. eggs } & \multirow{2}{*}{ No. larvae } & \multicolumn{2}{|c|}{ No. adults } & \multirow{2}{*}{$\begin{array}{l}\text { No. dying } \\
\text { as larvae }\end{array}$} & \multirow{2}{*}{$\frac{\text { Larvae }}{\text { Eggs }}$} & \multirow{2}{*}{$\frac{\text { Adults }}{\text { Larvae }}$} \\
\hline & & & & $\sigma^{x} \sigma^{x}$ & 우 & & & \\
\hline 0 & mated & 42 & 30 & 11 & 12 & 2 & .71 & .77 \\
\hline 722 & mated & 80 & 64 & 27 & 20 & 8 & .80 & .73 \\
\hline 1444 & mated & 53 & 40 & 4 & 3 & 25 & .75 & .17 \\
\hline 0 & unmated & 42 & 39 & 35 & & 4 & .93 & .90 \\
\hline 722 & unmated & 47 & 43 & 36 & & 7 & .92 & .84 \\
\hline 1444 & unmated & 50 & 44 & 12 & & 24 & .88 & .27 \\
\hline
\end{tabular}


There are insufficient data to state whether haploids and diploids are affected differentially when irradiated at 13-15 hours of age.

\section{Discussion}

Comparisons of radiosensitivity among individuals differing in ploidy have appeared in the literature in an attempt to evaluate the extent of chromosomal ("genetic") and cytoplasmic ("physiological") injury. Since differences in the number of chromosome sets are the most obvious distinguishing characteristics, the occurrence of a differential lethal effect has been taken as a criterion that nuclear injury has taken place. It is less obvious, but pertinent, that different metabolic conditions may exist in diploids and polyploids. Investigations herein reported of x-ray effects for haploids and diploids of Habrobracon suggest that radiosensitivity cannot be correlated with genome number at all stages in the life cycle. The differential radiosensitivity between haploids and diploids depends upon the stage of development at which they are irradiated. Haploids are more resistant than diploids during cleavage, equally resistant immediately following cleavage, and less resistant than diploids during the larval, prepupal, and pupal stages. One might inquire, therefore, if a differential effect between diploids and polyploids is an adequate criterion for distinguishing between chromosomal and cytoplasmic injury.

Most of the investigators who have reported a differential effect upon survival have found that the individuals with the greater number of chromosome sets are more resistant. Some of them (Müntzing, 1941; Latarjet and Ephrussi, 1949; Clark and Kelly, 1950; Clark and Mitchell, 1951) have suggested that (1) chromosome breakage occurs with the resultant loss of acentric fragments, and (2) there is a greater chance for individuals with higher ploidy to retain unbroken chromosomes that could compensate for the homologous fragments that are lost.

There are some observations that are difficult to reconcile with interpretations of radiation injury purely in terms of a chromosome breakage hypothesis. Studies on diploid and polyploid cereals have correlated gross observations on survival with the number of chromosome breaks (Fröier, Gelin and Gustafsson, 1941; Smith, 1943, 1946). These investigators have shown that polyploids, even though more resistant than diploids, have more anaphase bridges and chromosome fragments than comparable diploids. Fröier, Gelin and Gustafsson (1941) have shown that the germination and sprouting ability of polyploids were unimpaired even when 50 per cent of the mitoses had bridges and fragments, but the growth of the diploids was impaired with much less nuclear disturbance. Further, they showed that at high doses (50,000-60,000 r) nuclei of Avena sativa, a hexaploid, are still able to divide even if the chromosomes are fragmented to the extent of discontinuity. Marshak and Bradley (1944) have shown that mitotic inhibition is inversely proportional to the number of chromosomes, but independent of chromosome length. They suggest that this indicates an effect upon the centromeres.

If a chromosomal basis for injury is to be postulated, then a different mechanism must be used to explain the fact that haploid embryos of Habrobracon are more resistant than diploids when treated during cleavage. The observations by Fröier, Gelin and Gustafsson (1941) and Smith (1943, 1946) on cereals and by Bishop (1950) on Tradescantia, that the number of chromosome breaks following $\mathrm{x}$-radiation is proportional to the number of chromosomes, would suggest that the 
diploid nuclei of Habrobracon incur twice as many chromosome breaks as comparable haploid nuclei. One might reason that the diploids would be more sensitive than the haploids because they have received twice as much injury per nucleus. It has already been noted, however, that polyploids with more chromosome breaks per nucleus are more resistant than diploids with fewer chromosome breaks per nucleus. Differences between the stages of development that allow haploids to be more resistant at one stage and more sensitive at another should perhaps be considered. A number of obvious differences exist between the cleavage stage and the later post-embryonic stages of Habrobracon. During cleavage there is a syncytium with the nuclei dividing rapidly and synchronously throughout the embryo while in later embryonic and the post-embryonic stages cells are present with active proliferation being restricted to localized regions. There is little differentiation in the embryos during cleavage. Whether or not these differences have anything to do with the reversal in radiosensitivity is not known.

If differential radiosensitivity is to be taken as a criterion of chromosomal injury, then the equivalent radiosensitivity of haploid and diploid embryos when $\mathrm{x}$-rayed immediately after cleavage must be taken to mean that extra-chromosomal factors are involved. The radioresistance is increasing rapidly at this time and, therefore, a slight lag in development between haploids and diploids could result in a large difference in radiosensitivity. Kelly (unpublished), using 50 per cent hatchability as the criterion for comparative lethality, has shown that haploid embryos increase in resistance from a dose of about $200 \mathrm{r}$ during cleavage to $7000 \mathrm{r}$ in about four hours. Lamy and Muller (1939) found that diploid and triploid Drosophila when treated as embryos were equally radiosensitive. They explained this by assuming that death was due to a "non-genetic" ("physiological") type of injury. The data reported in the present paper suggest that the Drosophila embryos were $\mathrm{x}$-rayed after cleavage.

Embryos $\mathrm{x}$-rayed during cleavage or in early blastema are arrested in development during the egg state or not at all. Post-embryonic development is normal. Embryos x-rayed at a later stage, however, may show a post-embryonic lag in development and become arrested at the larval stage. Dent and Amy (1950) treated embryos and larvae of Habrobracon with $\mathrm{P}^{32}$. They found a lag and an arresting of development at the larval stage. Henshaw and Henshaw (1933) and Packard (1935) have determined the sensitivity of Drosophila eggs when x-rayed during different stages of embryonic development using hatchability as the criterion of radiosensitivity. Since in Habrobracon older embryos when x-rayed may hatch normally but may show deleterious effects after hatching, it seems that hatchability alone is not an adequate measure of radiosensitivity. Kelly (unpublished) showed that an x-ray dose of $30,000 \mathrm{r}$ had no effect on the hatchability of older embryos of Habrobracon. Such embryos, however, would not have developed beyond the larval stage.

Although its significance is not known, the observation that nuclei of embryos arrested during cleavage are considerably larger following irradiation is in agreement with the reports of enlarged nuclei by Mottram (1933) for Colpidium, Jenson's rat sarcoma and bean roots, and by Harrington and Koza (1951) for grasshopper embryos.

These data on Habrobracon show that radiosensitivity cannot be correlated with genome number throughout the life cycle. It is difficult, therefore, to pose a single 
generalization that will explain these diverse data from the standpoint of chromosomal injury. It may also be difficult to explain them on the basis of a quantitative difference of some chemical constituent. It is possible that there is no single "mostradiosensitive" mechanism, but that the relative sensitivities of the cellular materials change during development and that different mechanisms may be primarily involved at different stages.

The authors wish to thank Dr. A. R. Whiting for her many helpful suggestions during the preparation of this manuscript, and Dr. D. S. Grosch for his critical reading of the manuscript.

\section{SUMMARY}

1. Comparison of radiosensitivity of haploids and diploids of Habrobracon shows that the stage of development at which the animals are x-rayed is important in determining the relative sensitivity between these groups. When embryos are $\mathrm{x}$-rayed during cleavage, haploids are more resistant than diploids; when embryos are $\mathrm{x}$-rayed immediately after cleavage has been completed (blastema stage), haploids and diploids are equally radiosensitive.

2. Embryos $\mathrm{x}$-rayed during cleavage or early blastema are deleteriously affected during the egg stage or not at all. Those that hatch complete post-embryonic development normally. Older embryos when $\mathrm{x}$-rayed may hatch, but post-embryonic development is slowed down and many of the individuals are arrested in development as larvae. Hatchability, therefore, is not an adequate criterion of radiosensitivity for older embryos.

3. Embryos that are $\mathrm{x}$-rayed during cleavage and fail to hatch are arrested in cleavage or in early blastema. The nuclei are arrested at interphase and become enlarged up to four times the diameter of untreated nuclei.

4. Since the differential radiosensitivity between haploids and diploids depends upon the stage of development at which they are irradiated, it is difficult to pose a single hypothesis that will account for these facts. It seems reasonable to consider that the relative sensitivities of the cellular materials change during development and that different mechanisms may be primarily involved at different stages.

\section{LITERATURE CITED}

Bishop, C. J., 1950. The influence of polyploidy on the x-ray sensitivity of cells. Rec. Gen. Soc. Amer., 19: 88.

Clark, A. M., AND E. M. Kelly, 1950. Differential radiosensitivity of haploid and diploid prepupae and pupae of Habrobracon. Cancer Res., 10: 348-352.

Clark, A. M., And C. J. Mitchell, 1951. Radiosensitivity of haploid and diploid Habrobracon during pupal development. J. Exp. Zool., 17: 489-498.

Dent, J. N., And R. L. Amy, 1950. Developmental effects observed in Habrobracon after exposure to beta radiation. Growth, $14: 113-121$.

Fröier, K., O. Gelin and A. Gustafsson, 1941. The cytological response of polyploidy to x-ray dosage. Bot. Notiser, $2: 199-216$.

Harrington, N. J., and R. W. Koza, 1951. Effect of x-radiation on the desoxyribonucleic acid and on the size of grasshopper embryonic nuclei. Biol. Bull., 101: 138-150.

Henshaw, P. S., and C. T. Henshaw, 1933. Changes in susceptibility of Drosophila eggs to x-rays. Part I. Radiology, 21: 239-250.

Lamy, R., ANd M. J. Muller, 1939. Evidence of the non-genetic nature of the lethal effect of radiation of Drosophila embryos. Proc. 7th Int. Congr. Genet., Supp., 180-181. 
Latarjet, R., and B. Ephrussi, 1949. Courbes de survie de levures haploides et diploides soumises aux rayons x. C. R. Acad. Sci. Paris, 229: 306-308.

Marshak, A., and M. Bradley, 1944. X-ray inhibition of mitosis in relation to chromosome number. Proc. Nat. Acad. Sci., 30: 231-237.

Mottram, J. C., 1933. Changes in the non-dividing nucleus following gamma radiation. $J$. Roy. Micr. Soc., 53 : 213-219.

Müntzing, A., 1941. Differential response to x-ray treatment of diploid and tetraploid barley. D. Fysiograph Sallskap. (Lund.) Forhandl., 2: 1-10.

PACKARD, C., 1935. The relation between age and radiosensitivity of Drosophila eggs. Radiology, 25 : 223-230.

Sмiтн, L., 1943. Relation of polyploidy to heat and x-ray effects in the cereals. J. Hered., 34 : $130-134$.

Smith, L., 1946. A comparison of the effects of heat and x-rays on dormant seeds of cereals, with special reference to polyploidy. J. Agr. Res., 73: 137-158.

Stadler, L. J., 1929. Chromosome number and the mutation rate in Avena and Triticum. Proc. Nat. Acad. Sci., 15: 876-881.

Whiting, A. R., and C. H. Bostian, 1931. The effects of x-radiation of larvae in Habrobracon. Genetics, 16: 659-680.

Whiting, P. W., 1943. Multiple allelles in complementary sex determination. Genetics, 28 : 365-382. 


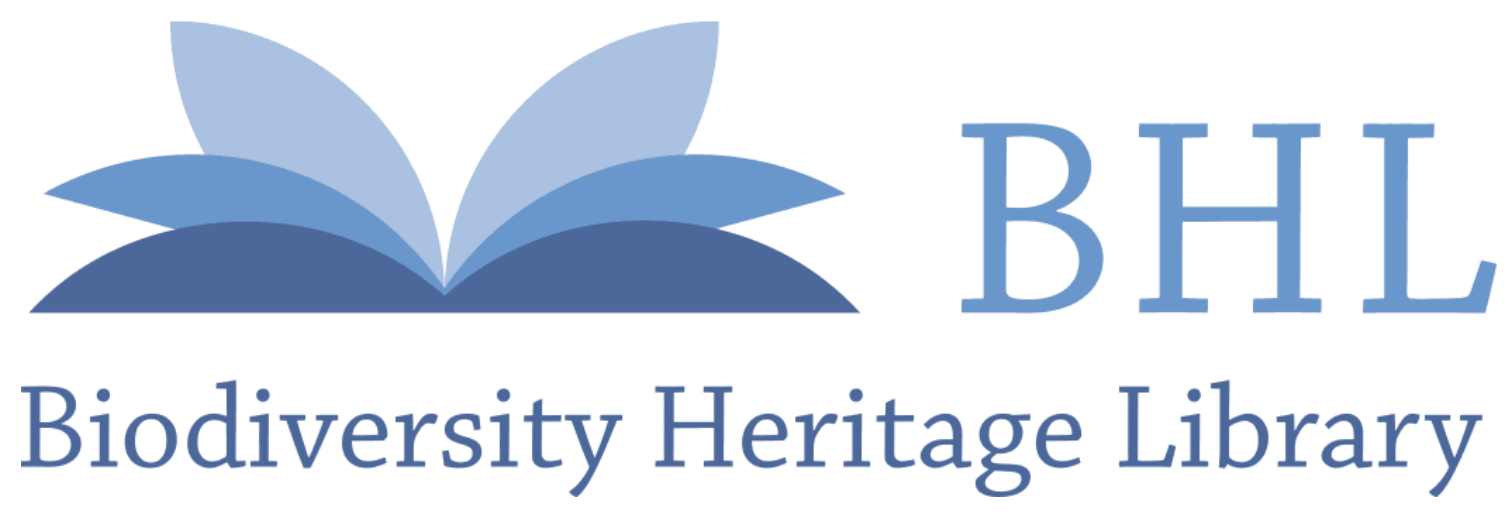

Clark, Arnold M. and Mitchell, C J. 1952. "EFFECTS OF X-RAYS UPON HAPLOID AND DIPLOID EMBRYOS OF HABROBRACON." The Biological bulletin 103, 170-177. https://doi.org/10.2307/1538443.

View This Item Online: https://www.biodiversitylibrary.org/item/17391

DOI: https://doi.org/10.2307/1538443

Permalink: https://www.biodiversitylibrary.org/partpdf/2322

\section{Holding Institution}

MBLWHOI Library

\section{Sponsored by}

MBLWHOI Library

\section{Copyright \& Reuse}

Copyright Status: In copyright. Digitized with the permission of the rights holder.

License: http://creativecommons.org/licenses/by-nc-sa/3.0/

Rights: https://biodiversitylibrary.org/permissions

This document was created from content at the Biodiversity Heritage Library, the world's largest open access digital library for biodiversity literature and archives. Visit BHL at https://www.biodiversitylibrary.org. 